\title{
Excretion of Amino Acids by Patients with Psoriasis Ingesting Two Levels of the Same Protein
}

\author{
By Walter D. Block and Mary H. Westhoff
}

The amounts of 27 amino acids and other ninhydrin-reacting substances were determined by ion-exchange chromatography in the urine of patients with psoriasis, eating diets containing 54 and $104 \mathrm{Gm}$. of protein from the same source. Regardless of level of protein intake, asparagine plus glutamine, histidine, glycine, and taurine or lysine contents of urine accounted for between 55 and 64 per cent of the total amount of amino acids present. This nucleus of amino acids, with the exception of lysine, was the same as in control individuals fed the same diets. The amount of amino acids in the urine increased when the protein intake was doubled, but only lysine, $\alpha$-aminoadipic acid, and cystathionine excretion was increased at least twofold. No outstanding differences in amino acid excretion were found between patients with psoriasis and control subjects. (Metabolism 15: No. 1, January, 46-52, 1966)

$I^{N}$ N PSORIASIS a high cellular activity of the epidermis exists, caused mainly by rapidly proliferating epidermal cells and increased vascularity of the corium. Microscopic examination of the psoriatic lesion reveals a thickening of the epidermis with loose lamellar hyperkeratotic scales, alternating with islands of parakeratosis containing nuclear remains. Because these hyperkeratotic and parakeratotic scales contain protein, or protein-like substances, it is possible that individuals with psoriasis may differ from nonpsoriatic individuals in their qualitative and quantitative requirements for amino acids to meet this increased need for synthesis of epidermal protein. Such a difference in requirements might be reflected in the alteration of the quantities of the individual amino acids present in the urine when diets containing low and high amounts of the same protein are fed.

Hubbard and co-workers ${ }^{1}$ have reported the amino acid content of urine from patients with psoriasis eating diets containing uncontrolled amounts of protein from various sources. Although the amount of protein intake and the excretion of most of the amino acids do not seem to be related, at least in normal individuals, ${ }^{2,3}$ Block et al. ${ }^{4}$ have shown that protein source does influence the output of 1 - and 3-methylhistidine, anserine ( $\beta$-alanyl-1-methylhistidine), and carnosine ( $\beta$-alanylhistidine).

In the following study, patients with psoriasis vulgaris were fed diets con-

From the Department of Dermatology, Biochemical Research Laboratories, University of Michigan Medical Center, Ann Arbor, Michigan.

Supported in part by U. S. Public Health Service Grants GM-04413-09 and 5M01FR-42-04.

Received for publication Aug. 18, 1965.

Walter D. Block, Ph.D.: Assoc. Prof. of Biological Chemistry, Dept. of Dermatology, University of Michigan Medical School, Ann Arbor, Mich. Mary H. Westhoff, A.B.: Research Assistant, Dept. of Dermatology, University of Michigan Medical School, Ann Arbor, Mich. 
Table 1.-Composition of Diets

\begin{tabular}{|c|c|c|}
\hline & $54 \mathrm{Gm}$. Protein & $104 \mathrm{Gm}$. Protein \\
\hline & Gm. & $\mathrm{Gm}$. \\
\hline \multicolumn{3}{|l|}{ Constants: } \\
\hline Milk & 1200 & 2400 \\
\hline Bread & 95 & 190 \\
\hline Canned pears & 100 & 100 \\
\hline Canned peaches & 100 & 100 \\
\hline Orange juice & 300 & 300 \\
\hline \multicolumn{3}{|c|}{ Multivitamin supplement ${ }^{*}-1$ daily } \\
\hline \multicolumn{3}{|l|}{ Variables: $\dagger$} \\
\hline Lettuce & Salad oil & \\
\hline Cornstarch & Butter & \\
\hline Jelly & Sugar & \\
\hline Soft drinks & Plain hard candy & \\
\hline
\end{tabular}

"Atlavite, Brewer and Co., Inc., Worcester, Mass.

tAmounts fed varied according to the caloric needs of the subject.

taining 2 levels of the same protein, and the amino acid content of their urine determined by quantitative ion-exchange chromatography.

\section{Procedures}

Subjects. Three patients with psoriasis, one female, F (age: 19 , height: $5^{\prime} 3^{\prime \prime}$, weight: 64 Kg.), and two males, $\mathrm{H}$ (age: 21 , height: $6^{\prime}$, weight: $85 \mathrm{Kg}$.) and $\mathrm{T}$ (age: 23, height: 5'91/2", weight: $79 \mathrm{Kg}$ ), served as subjects. All had extensive psoriasis of long duration; none of them received any oral or intravenous therapy for psoriasis for at least 1 month before the study, or therapy of any type during the study. The patients were ambulatory but lived in the metabolic unit of the medical center throughout the study.

Each subject underwent a thorough physical examination which included clinical laboratory tests to ensure that they had normal liver and kidney function.

Diets. The foods comprising the 54 and $104 \mathrm{Gm}$. protein diets are listed in Table 1 . Milk contributed $42 \mathrm{Gm}$. and bread $8 \mathrm{Gm}$. of protein to the $54 \mathrm{Gm}$. protein diet; in the $104 \mathrm{Gm}$. protein diet, milk contributed $84 \mathrm{Gm}$. and bread $16 \mathrm{Gm}$. of protein. The remaining $4 \mathrm{Gm}$. of protein in each diet came from a variety of foods which were used mainly as sources of calories.

Plan of Study. The subjects were given the $54 \mathrm{Gm}$. protein diet for a period which varied from 28 days for subject $F$ to 6 days for $T$. The $104 \mathrm{Gm}$. protein diet was fed for 7 to 8 days.

Collection and Analysis of Urine. Twenty-four hour urine collections were made during the study. Phenol and $\mathrm{HCl}$ were used as preservatives, and the samples kept frozen at -20 C. until analyzed. A minimum of 3,24 hour collections from each diet period were prepared for analysis by the method of Stein ${ }^{5}$ and analyzed for 27 amino acids and other ninhydrin-reacting substances by the quantitative ion-exchange chromatographic technic of Spackman et al. ${ }^{6}$

Preparation and Analysis of Food Samples. Milk was lyophilized, a weighed portion of the powder was placed in $6 \mathrm{~N} \mathrm{HCl}$ in a Pyrex tube, the tube sealed, and heated for 24 hours at $120 \mathrm{C}$. $\mathrm{HCl}$ was removed under vacuum, the residue dissolved in a small amount of water, and transferred quantitatively to a volumetric flask with buffer $\left(\mathrm{pH} \mathrm{2.2)}{ }^{6}\right.$ Bread was dried in an oven at $75 \mathrm{C}$. for 24 hours and ground to a fine powder. The powder was prepared for analysis of total amino acids in the same manner as the milk powder.

The content of 19 amino acids and other ninhydrin-reacting substances in the preparations was determined by ion-exchange chromatography. 6 


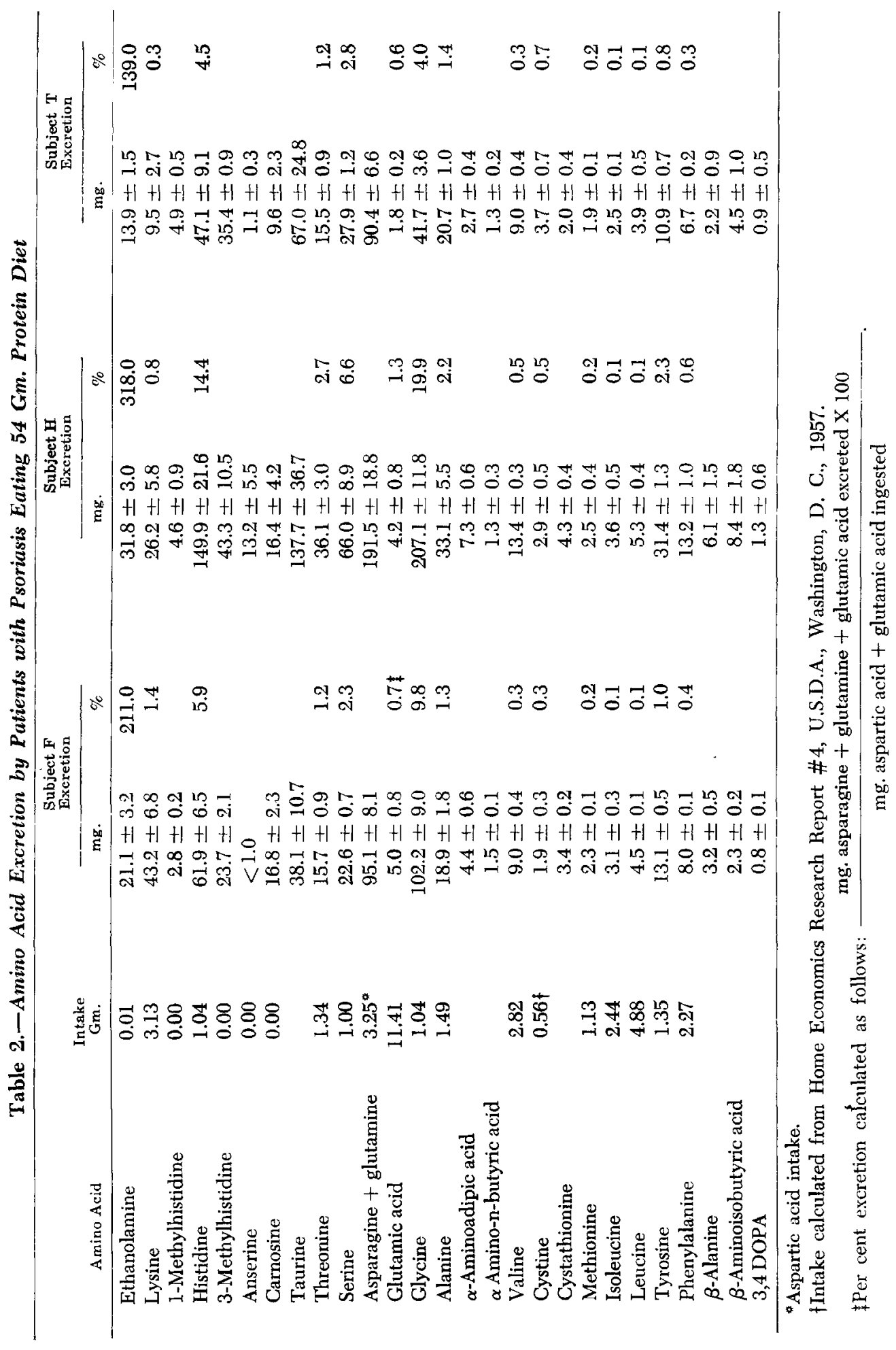




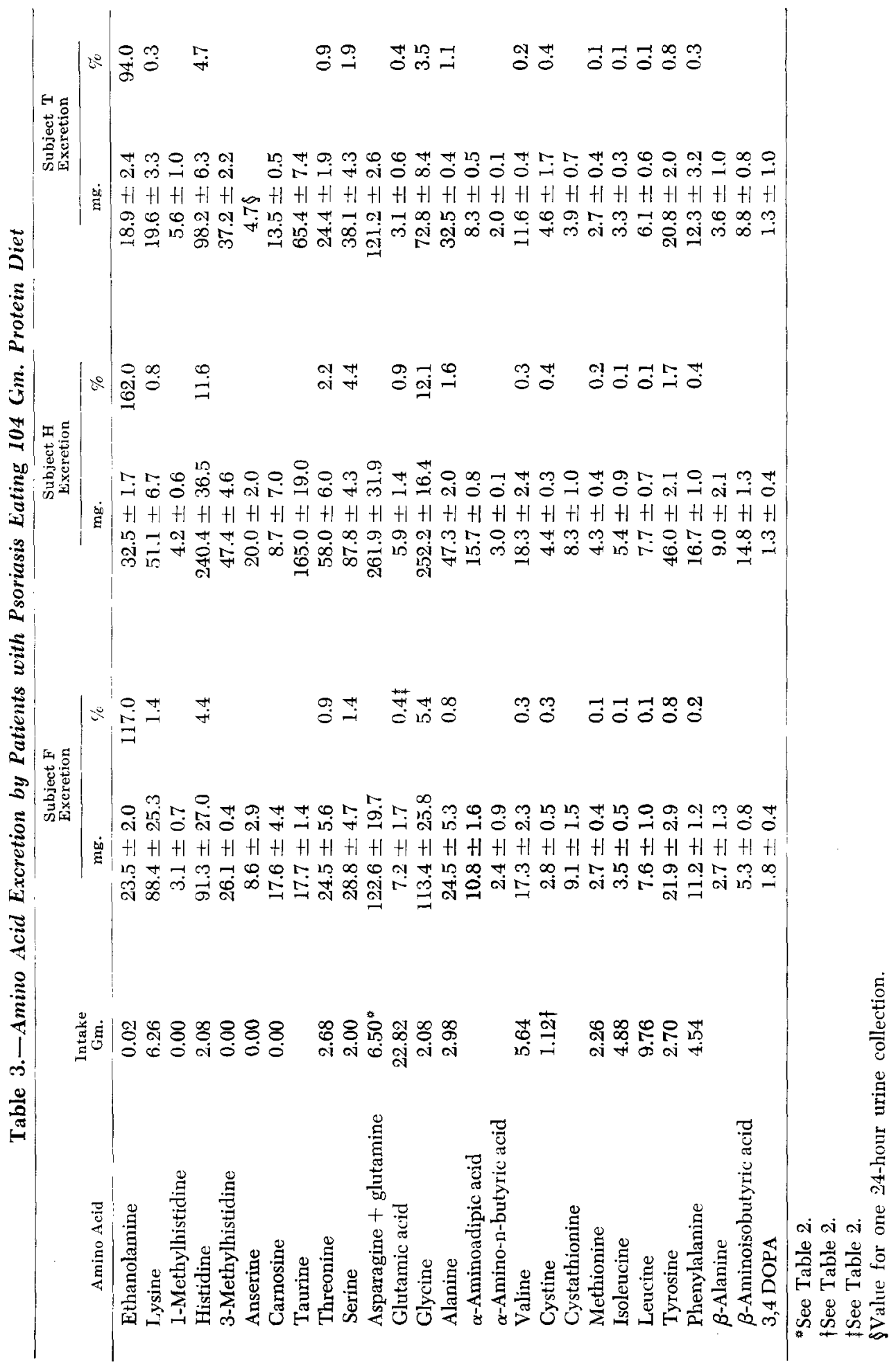




\section{RESULTS}

The amounts of 27 amino acids and other ninhydrin-reacting substances excreted by the 3 subjects while they were ingesting the $54 \mathrm{Gm}$. protein diet are given in Table 2. Excretion is expressed in $\mathrm{mg}$. of the individual amino acids, and in per cent of the ingested amino acid excreted. Table 3 gives the results obtained when the subjects were eating the $104 \mathrm{Gm}$. protein diet.

In general, increasing the protein intake from 54 to $104 \mathrm{Gm}$. caused increased amounts of the following 21 amino acids to appear in the urine of all the subjects: ethanolamine, lysine, histidine, anserine, threonine, serine, asparagine + glutamine, glutamic acid, glycine, alanine, $\alpha$-aminoadipic acid, $\alpha$-amino-n-butyric acid, valine, cystine, cystathionine, methionine, isoleucine, leucine, tyrosine, phenylalanine and $\beta$-aminoisobutyric acid (Tables 2 and 3 ).

Of these 21 amino acids, only 3 , lysine, $\alpha$-aminoadipic acid, and cystathionine excretion by all 3 subjects was increased at least twofold when the protein intake was doubled.

The excretion of the methylated dipeptide of $\beta$-alanine and histidine, anserine, was increased approximately eightfold, from $<1.0$ to $8.6 \mathrm{mg}$. by subject $\mathrm{F}$, and approximately fourfold, from 1.1 to $4.7 \mathrm{mg}$. by subject $\mathrm{T}$ when the protein intake was increased from 54 to $104 \mathrm{Gm}$; subject $\mathrm{H}$ only increased his excretion from 13.2 to $20.0 \mathrm{mg}$. On the other hand, the excretion of carnosine, the nonmethylated dipeptide of $\beta$-alanine and histidine, was approximately the same for subject $\mathrm{F}$, decreased from 16.4 to $8.7 \mathrm{mg}$. for subject $\mathrm{H}$, and increased from 9.6 to $13.5 \mathrm{mg}$. for subject $\mathrm{T}$ when the protein intake increased (Tables 2 and 3 ).

The excretion of 1-methylhistidine and 3-methylhistidine remained essentially constant for each subject regardless of the amount of protein intake.

Taurine excretion by subject $F$ decreased approximately one-half when her intake of protein was doubled; subject $\mathrm{T}$ also showed a decrease in excretion, but subject $H$ increased his excretion by $27.3 \mathrm{mg}$.

Excretion of $\beta$-alanine and 3,4 DOPA was erratic and seemed to bear no consistent relationship to protein intake.

Asparagine + glutamine, taurine, histidine and glycine content of urine accounted for between 55 and 64 per cent of the total amino acid content of the urine for subjects $H$ and $T$ regardless of level of protein intake; lysine replaced taurine in this group for subject $F$ (Tables 2 and 3 ).

\section{Discussion}

Epidermal cells contain, among other components, protein and proteinlike substances (which are composed of amino acids), and free amino acids; all these contain nitrogen. Although nitrogen and amino acids exist in psoriatic epidermis in no greater amounts than in epidermis from nonpsoriatic individuals, ${ }^{7}$ the fact that the epidermis in psoriasis is proliferating more rapidly than normal indicates that the rate of use and/or metabolism of protein must be abnormal in this disease.

Schamberg et al., ${ }^{8}$ in studies of nitrogen balance on patients with psoriasis, found excessive nitrogen retention when the patients were fed adequate levels 
of protein; remission of the dermatologic symptoms were noted with a low protein intake. In correlating the biochemical finding with the clinical symptoms, the assumption was made that the retained nitrogen (or protein) went to form the excessive scales common in psoriasis. Other investigators ${ }^{9,10}$ were unable to substantiate this finding of nitrogen retention in patients with psoriasis, although recently Lerner and Lerner, ${ }^{11}$ in a study with one patient with psoriasis, noted improvement in the subject's lesions when nitrogen intake was low, and worsening when a steak diet (high protein) was given.

Nitrogen excretion, however, is an estimation of gross protein metabolism in the body. Protein is composed of amino acids combined in peptide linkages, and if an abnormality in protein metabolism exists in psoriasis, a study of the excretion of the individual amino acid should be more discriminatory in detecting such an aberration.

Because each individual excretes amino acids at a level characteristic to himself, any differences in excretion noted between individuals must be interpreted conservatively. In the present investigation, although some differences in the excretion of amino acids were found between patients with psoriasis and nonpsoriatic individuals fed 2 levels of the same protein, none of them appear to be of outstanding importance.

The patients with psoriasis tended to increase their excretion of total amino acids more than did non-psoriatic individuals when the protein intake was increased from 54 to $104 \mathrm{Gm}^{3}$ This difference was due in part to increased excretion of lysine, histidine, and glycine; the remainder of the increase was spread among the other amino acids so that no one increased in outstanding amounts. The amino acids, asparagine + glutamine, histidine, glycine, and taurine or lysine, comprised the bulk of the urinary amino acids in the patients with psoriasis regardless of level of protein intake. This nucleus, with the exception of lysine, was the same in control individuals. ${ }^{3}$

Nonpsoriatic individuals excreted $\alpha$-aminoadipic acid and cystathionine in amounts that paralleled protein intake, e.g., if the protein intake increased twofold, $\alpha$-aminoadipic acid excretion increased twofold. ${ }^{3}$ In addition to $\alpha$-aminoadipic acid and cystathionine, patients with psoriasis also excreted lysine in amounts parallel to protein intake. $\alpha$-Aminoadipic acid is an intermediate in the metabolism of methionine to cystine. ${ }^{12}$ Both lysine and methionine are classified as amino acids essential for nitrogen balance in man and must be obtained from exogenous sources. ${ }^{13}$ This is not true for $\alpha$ aminoadipic acid and cystathionine, which are made in the body in amounts adequate for its metabolic needs.

The diets fed in this study contain no sources of 1-methylhistidine, 3-methylhistidine, anserine, and carnosine. Both 1-methylhistidine and 3-methylhistidine were found in the urine, but the excretion remained relatively constant regardless of level of protein intake, and the amounts were similar to those excreted by nonpsoriatic individuals fed the same diets. ${ }^{3}$ Hubbard et al. ${ }^{1}$ reported finding large amounts of 1-methylhistidine in the urine of some patients with psoriasis eating uncontrolled diets. That urinary l-methylhistidine in man arises from dietary sources of anserine was shown by Datta and 
Harris, ${ }^{14}$ and reconfirmed in quantitative studies by Block et al. ${ }^{+}$Lack of control of dietary protein source thus may have caused the high urinary 1methylhistidine excretion observed by Hubbard et al. ${ }^{1}$

A patient with psoriasis fed a controlled diet containing $50 \mathrm{Gm}$. of beef excreted $15.2 \mathrm{mg}$. of 1-methylhistidine or 85 per cent of the amount ingested; when the beef intake was increased to $150 \mathrm{Gm}$. daily, the patient excreted $45.1 \mathrm{mg}$. or 84 per cent of the ingested 1-methylhistidine. The 1-methylhistidine moiety of the dipeptide anserine accounted for 88 per cent of the total 1methylhistidine in the diet." These results leave little doubt that urinary 1methylhistidine in patients with psoriasis arises directly from protein source.

In both patients and control subjects in the present study, the excretion of anserine, the methylated dipeptide of $\beta$-alanine and histidine; and carnosine, the nonmethylated dipeptide of the same 2 amino acids, was erratic and seemed to bear no relationship to level of protein intake. ${ }^{3}$

\section{ACKNOWLEDGMENTS}

We wish to thank Raymond Glowacki, M.D., and John Winfield, M.D., for the clinical care of the patients.

\section{REFERENCES}

1. Hubbard, R. W., Steele, B. F., Spear, V., and Block, W. D.: Amino acid content of blood and urine in psoriasis. J. Invest. Derm. 38:183, 1962.

2. Stein, W. H., Bearn, A. G, and Moore, S.: The amino acid content of the blood and urine in Wilson's disease. J. Clin. Invest. 33:410, 1954.

3. Block, W. D., Markovs, M. E., and Steele, B. F.: Effect of protein and of free L-methionine intake on amino acid excretion by human subjects. J. Nutr. 86:1, 1965.

4. -, Hubbard, R. W., and Steele, B. F.: Excretion of histidine and histidine derivatives by human subjects ingesting protein from different sources. J. Nutr. 85:419, 1965.

5. Stein, W. H.: A chromatographic investigation of the amino acid constituents of normal urine. J. Biol. Chem. 201:45, 1953.

6. Spackman, D. H., Stein, W. H., and Moore, S.: Automatic recording apparatus for use in the chromatography of amino acids. Anal. Chem. 30:1190, 1958.

7. Cornish, H. H., Block, W. D., and Lea,
W. A., Jr.: Distribution of lipids and free amino acids in psoriatic scales. J. Invest. Derm. 32:43, 1959.

8. Schamberg, J. F., Kolmer, J. A., Ringer, A. I., and Raiziss, G. W.: Protein metabolism in psoriasis. J. Cut. Dis. 31:803, 1913.

9. Geber, H.: Nitrogen- und Schwelfelstoffwechsel-Untersuchungen bei Psoriasis vulgaris. Dermat. Ztschr. 20:377, 1913.

10. Block, W. D., Lea, W. A., Jr., Curtis, A. C., and Cannon, E. F.: I. Nitrogen balance and sulfur excretion studies in psoriasis. J. Invest. Derm. 30:287, 1958.

11. Lerner, M. R., and Lerner, A. B.: Psoriasis and protein intake. Arch. Derm. 90:217, 1964.

12. Kleiner, I. S., and Orten, J. M.: Biochemistry, 6th ed. St. Louis, The C. V. Mosby Co., 1962.

13. Rose, W. C.: The amino acid requirements of adult man. Nutr. Abst. Rev. 27:631, 1957.

14. Datta, S. P., and Harris, H.: Dietary origin of urinary methylhistidine. Nature (London) 168:296, 1951.

\footnotetext{
*Unpublished data.
} 